\title{
Improvement of the functional recovery of the upper limb in hemiplegic patients by the use of the technique of induced stress therapy
}

\author{
Teddy Bofosa ${ }^{1} \odot$, Eric $\operatorname{Kam}^{2} \odot$, Betty Miangindula ${ }^{1} \odot$, Constant Nkiama ${ }^{1} \odot$, Tharcisse Kayembe $^{3} \odot$ \\ ${ }^{1}$ Department of Physical Medicine and Rehabilitation, Kinesiology Service, Laboratory of Medical Fitness and Functional Exercise, \\ University of Kinshasa, Faculty of Medicine, University Clinics of Kinshasa, Kinshasa, Democratic Republic of Congo \\ ${ }^{2}$ Department of Physical Medicine and Rehabilitation, Adult Neuro-Rehabilitation Unit, University of Kinshasa, Faculty of Medicine, \\ University Clinics of Kinshasa, Kinshasa, Democratic Republic of Congo \\ ${ }^{3}$ Service of Neurology, Neuro-Psychopathological Center, University of Kinshasa, Faculty of Medicine, Kinshasa, Democratic Republic \\ of Congo
}

\begin{abstract}
Objectives: To investigate the effects of the induced stress therapy technique in functional recovery of the upper limb in hemiplegic patients.

Methods: We conducted a longitudinal study that consisted in following the evolution of the functional recovery of the upper limbs of 60 hemiplegic subjects of the center for physical disabilities of Kinshasa subjected to a program of induced stress therapy for a period of six months from April 2018 to October 2018. The Fugl Meyer scale and Action Research Arm test allowed us to see the effects of this treatment. The parametric $t$ test of student allowed us to compare the averages before and after the treatment.

Results: After 6 months of the study, the results of our cases showed a very significant difference between the mean values of global motor skills scores at Action Research Arm between the beginning $(51 \pm 21 \%)$ and the end of treatment $(64 \pm 20 \% ; p<0.05)$. The difference in mean values at the Fugl Meyer scale was also very significant, both at overall scores and under-scores $(p<0.05)$. There is a very significant difference between older and younger patients compared to the mean values of their overall scores on the motor and independence scales $(p<0.05)$.

Conclusions: We found that induced stress therapy significantly improved the level of functional recovery and autonomy at the Action Research Arm and Fugl Meyer scales. In addition, this improvement was a little slower in the hand than in the other segments of the upper limb.

Keywords: induced stress therapy, functional recovery, hemiplegic, upper limb
\end{abstract}

$\mathrm{H}$ emiplegia corresponds to an engine deficit linked to an impairment of the central nervous system [1]. Because of the path of the motor path and its decussating at the level of the bulbar pyramid, hemiplegia affects, in the majority of cases, the hemi-body opposite the injured cerebral hemisphere and according to the extent and location of the brain lesion, it may affect the upper limb and the face or lower limb more $[1]$.

Person [2] reported that $80 \%$ of hemiplegic pa- 
tients recover walking, while only 28 to $57 \%$ recover the grip [3, 4]. Delden also came to a similar conclusion as he thinks that $80 \%$ of hemiplegics have severe upper limb involvement, and that only 30 to $40 \%$ recover useful grasping [2].

Although it is the severity of the cerebral involvement which conditions the degree of motor and functional recovery [2], other factors are also decisive, including those related to the rehabilitation treatment, and which are related to its precocity, its repetitiveness and its active character.

In the Democratic Republic of Congo, we have observed that most hemiplegic patients find it very difficult to recover the functionality of their upper limbs after the rehabilitation sessions. Since stress-induced therapy has been scientifically proven in functional recovery of the upper limbs, it is less used by rehabilitation professionals in Kinshasa. In addition, we have hardly found enough studies focused on upper limb rehabilitation.

Nevertheless, Bofosa et al. [5] conducted a study in our community, on the impact of induced stress therapy (IST) comparing two groups of patients, ie., those subjected to IST and a control group, but not have not studied the influence of sex, age and duration of disease in functional recovery after IST. The objective of this study is to evaluate the effects of stress therapy in hemiplegic subjects taking into account the sex, age and duration of the disease.

\section{METHODS}

\section{Nature and Period of Study}

We conducted a cross-sectional experimental study that tracked the evolution of upper limb functional recovery in hemiplegic subjects undergoing a stress-induced therapy program over a six-month period from April 2018 to October 2018.

\section{Framework of the Study}

We conducted the present experimental study in the rehabilitation center for physical disabilities of Kinshasa in the Democratic Republic of Congo.

The choice of this framework is justified: (a) Primo: he is renowned in the field of rehabilitation in Kinshasa; (b) Secondly, it has a large number of hemiplegic patients frequent; (c) Tertio: the regularity of hemiplegic patients at re-education sessions.

\section{Population of the Study}

The study was approved by the Ethics Committee of the Departement of Physical medicine and rehabilitation (Democratic Republic of Congo) (Number: A00-987 50) and was registered on the Clinical Trials Gov. Registry, with the number NCT 05860022 (12 Febuary 2018). All experiments were performed in accordance with relevant guidelines and regulations. Each hemiplegic subjects received information about the purpose and nature of the protocol. After reading and understanding the information, a statement at testing to informed consent was approved, obtained and signed by the hemiplegic subjects. This study consisted of a population of hemiplegic patients attending Kinshasa physical rehabilitation center.

\section{Criteria}

The following inclusion criteria were selected for this study: (a) To be a hemiplegic patient regularly followed at the rehabilitation center for the physically handicapped; (b) Have a card and a complete medical file; (c) Have an average age between 20 years and over; (d) To have freely consented to participate in this study; and (e) Have already followed more than 24 sessions. All patients who did not meet the inclusion criteria mentioned above were excluded.

\section{Sample}

A convenience sample of 60 hemiplegic patients from the rehabilitation center for disabled people. We divided these patients according to: sex (to realize the effect of sex on this recovery); age: to reveal the influence of age on the functional recovery of the upper limbs and the duration of the disease to see the effect of this time on this recovery.

\section{Scale and Test Used}

The Fugl Meyer scale allowed us to evaluate upper extremity motor skills in hemiplegic patients. Thanks to this scale, we measured the motor skills at the level of the shoulder; elbow and forearm. All tests were scored from 0 to 2 ( 0 : not done, 1: partially done, 2: totally done).

Action Research Arm Test (ARA), this test allowed us to measure the fine motor skills of the 
upper limbs of hemiplegic patients. It consists of four items: grab, hold, pinch and global movements. It has been rated 0-3 (0: Can not perform any part of the test; 1: Can perform part of the test; 2: Can perform the test but in abnormally long time or with great difficulty; Execute the test normally).

\section{Intervention Program}

The principles of the treatment consisted of: (a) respecting the fatigability of the patient; (b) fight against spasticity and avoid strengthening it; (c) fight against syncinesia; (d) adapt the exercises to the patient's abilities; and (e) let the patient do his own activities of daily living (ADL) within the limits of his abilities. The healthy limb being immobilized by an immobilization vest, an immobilization scarf or a velpo band, and the patient had to perform the different tasks or activities of daily life with the sick member. Different objects and toys were used to perform various tasks such as showering, combing hair, eating, writing, moving an object, etc. We also used other exercises involving the cognitive abilities of the patient (concentration, memorization, intention of movement), using different objects (hoops, pads, rings) and their characteristics (shape, size, color, weight), and adapting the instruction to obtain a movement allowing the stretching of the spastic muscle.

\section{Ethical Consideration}

All participants had consented to write to participate in the study according to the Helsinki Declarations. The information collected from participants was kept confidential. All authors declare originality and ethical approval of research. Responsibilities of research, responsibilities against local ethics commission are under the Authors responsibilities. The study was conducted under defined rules by the Local Ethics Commission guidelines and audits.

\section{Statistical Analysis}

Data from this study were captured on Microsoft Excel 2010 software and exported to SPSS software version 20.0 for Windows. We presented the results in the tables and figures as means, standard deviation, and percentage. To appreciate the effects of induced stress therapy on upper limb functionality, we used the student's parametric $t$ test. We compared the averages by age, sex and duration of illness.

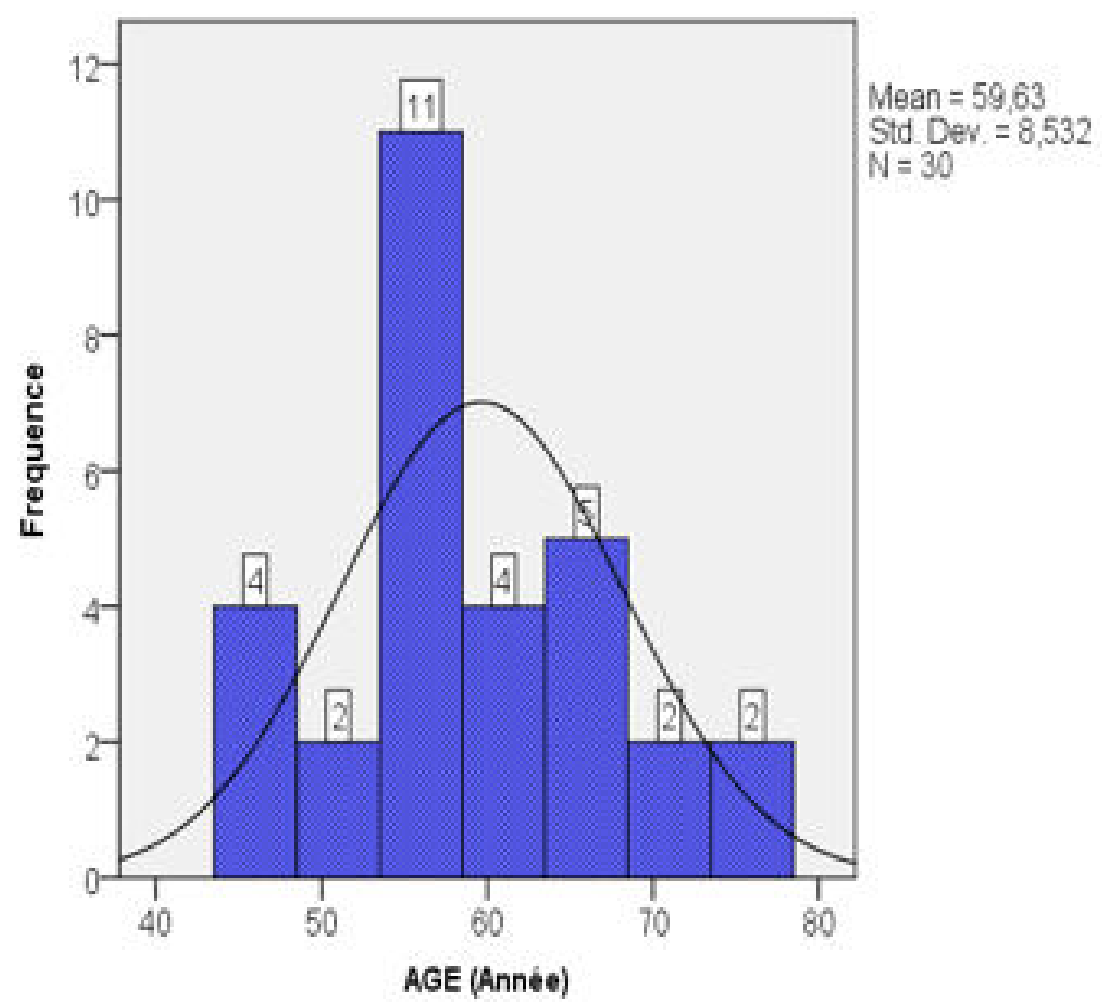

Fig. 1. Distribution of patients by age. 


\section{RESULTS}

Mean age of the patients was $59.6 \pm 8.5$ years, with extremes of 43 years and 79 years (Fig. 1). In this study, $63.3 \%$ of patients were men and $36.7 \%$ were women (Fig. 2).

There were $21(70 \%)$ ischemic strokes and $9(30)$ hemorragic strokes; the sign of laterality concerned the left hemi-body in $60 \%$ of cases 8 Table 1 ). These patients were in $53.3 \%$ of cases between 6 and 11 months of the disease, and $46.7 \%$ at least 12 months. In analysis of the influence of the program, there was a very significant difference in the mean values of the overall motor mobility scores at the ARA between the onset $(51 \pm 21 \%)$ and the end of the treatment (64 \pm $20 \%$ ), with a $p=0.000$; on the other hand, the analysis of the sub-scores did not show any significant difference in pinching (initially $3 / 18$ and $4 / 18$ at the end) and global movements (5/9 initially and 6/9 at the end), with a $p>0.05$ (Table 2). The difference in mean values at the Fugl Meyer scale was also very significant, both at the global scores and under the scores $(p=0.001)$.

Table 3 shows that the mean values of the overall ARA and Fugl Meyer scores showed no significant difference between patients who were less than 12 months and those who were more or less 12 months $(p>0.05)$. The same is true for the comparison of the mean values of the overall ARA and Fugl Meyer
Table 1. Distribution of patients by type of stroke, hemiplegic hemi body and duration of illness

\begin{tabular}{lcc}
\hline Parameters & $\mathbf{n}$ & $\mathbf{\%}$ \\
\hline Type of stoke & & \\
$\quad$ Ischemic & 21 & 70.0 \\
$\quad$ Hemorrhagic & 9 & 30.0 \\
$\begin{array}{c}\text { Hemicorps reached } \\
\text { Left }\end{array}$ & \\
\hline Right & 18 & 60.0 \\
Duration of disease (months) & 12 & 40.0 \\
\hline $6-11$ & 16 & \\
\hline $12-24$ & 14 & 43.3 \\
\hline
\end{tabular}

scores by sex, which also did not show a significant difference between men and women $(p>0.05)$ (Table 4). There was a significant difference between elderly and younger patients compared to the average values of their overall scores $(p<0.05)$ (Table 5).

\section{DISCUSSION}

This study involved 30 patients undergoing

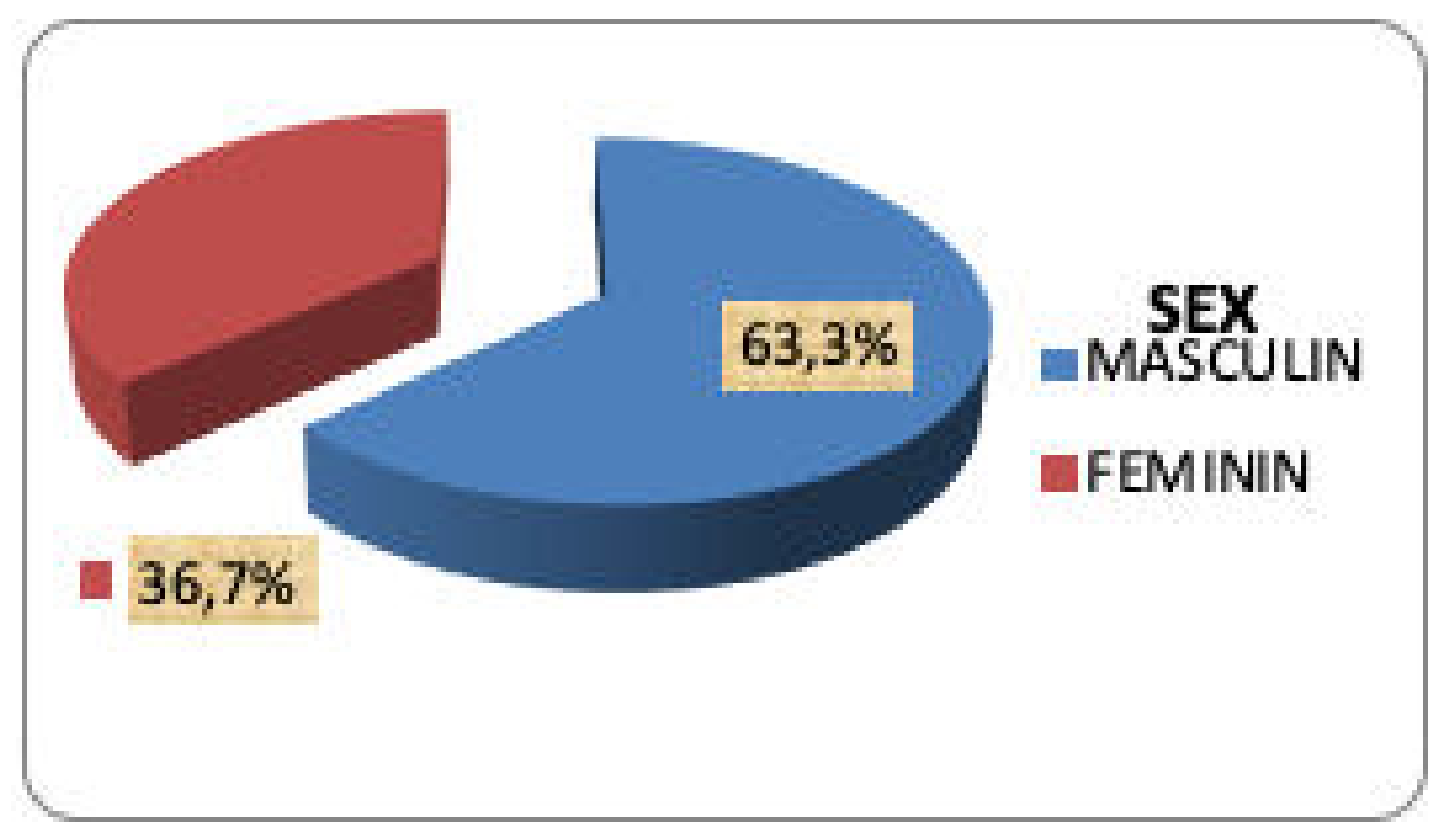

Fig. 2. Distribution of patients by gender. 
Table 2. Presentation of the functional and autonomy profile at the ARA and Fugl Meyer scales

\begin{tabular}{|lcccc}
\hline Parameters & Before & After & t & $\boldsymbol{p}$ value \\
\hline \% Global Ssore ARA & $51 \pm 21$ & $64 \pm 20$ & -8.901 & $\mathbf{0 . 0 0 2}$ \\
\hline Under scores ARA & & & & \\
\hline Enter /18 & $9 \pm 4$ & $12 \pm 4$ & -7.129 & $\mathbf{0 . 0 0 1}$ \\
\hline Hold /12 & $7 \pm 3$ & $9 \pm 3$ & -6.567 & $\mathbf{0 , 0 0 1}$ \\
\hline Pinch /18 & $3 \pm 2$ & $4 \pm 2$ & 1.32 & 0.06 \\
\hline Global Movements /9 & $5 \pm 1$ & $6 \pm 1$ & 1.34 & 0.06 \\
\hline \% of score global Fugl Meyer & $50 \pm 21$ & $65 \pm 17$ & -7.5 & $\mathbf{0 . 0 0 3}$ \\
\hline Under Fugl Meyer scores & & & & \\
\hline Shoulder/elbow/arm/30 & $16 \pm 7$ & $20 \pm 5$ & -6.8 & $\mathbf{0 . 0 0 6}$ \\
\hline Wrist /10 & $5 \pm 2$ & $7 \pm 2$ & -7.24 & $\mathbf{0 . 0 0 1}$ \\
\hline Hand /14 & $6 \pm 3$ & $8 \pm 3$ & -4.75 & $\mathbf{0 . 0 0 1}$ \\
\hline Coordination-speed /6 & $3 \pm 2$ & $4 \pm 1$ & -7.21 & $\mathbf{0 . 0 0 1}$ \\
\hline
\end{tabular}

Data are shown mean \pm Standard deviation. ARA $=$ Action Research Arm

Table 3. Presentation of the mean values of initial and end-of-treatment global functional and autonomy scores as a function of duration of illness

\begin{tabular}{llcccc}
\hline \multicolumn{2}{c}{ Parameters } & \multicolumn{2}{c}{ Duration of disease } & t & $p$ value \\
& & $<\mathbf{1 2}$ Month & $\mathbf{2 1 2}$ Month & & \\
\hline \% ARA & Before & $50 \pm 23$ & $53 \pm 20$ & -0.370 & 0.710 \\
& After & $62 \pm 23$ & $66 \pm 17$ & -0.55 & 0.58 \\
\% Fugl Meyer & Before & $50 \pm 23$ & $51 \pm 20$ & -0.200 & 0.830 \\
& After & $64 \pm 21$ & $65 \pm 14$ & -0.080 & 0.930 \\
\hline
\end{tabular}

Data are shown mean \pm Standard deviation. ARA $=$ Action Research Arm

Table 4. Presentation of the mean values of the initial global functional and autonomy scores and the end of treatment according to sex

\begin{tabular}{llcccc}
\hline \multicolumn{2}{c}{ Parameters } & \multicolumn{2}{c}{ Duration of disease } & t & $p$ value \\
& & Male & Female & & \\
\hline \% ARA & Before & $51 \pm 21$ & $53 \pm 22$ & -0.330 & 0.74 \\
& After & $66 \pm 20$ & $61 \pm 22$ & 0.66 & 0.51 \\
\% Fugl Meyer & Before & $50 \pm 21$ & $52 \pm 22$ & -0.240 & 0.81 \\
& After & $66 \pm 15$ & $62 \pm 21$ & 0.610 & 0.54 \\
\hline
\end{tabular}

Data are shown mean \pm Standard deviation. ARA $=$ Action Research Arm

rehabilitation, whose average age was $59.6 \pm 8.5$ years, with extremes of 43 years and 79 years. Male predominance was observed. The same trend has been described in other Congolese series in relation to the average age and male predominance [1,2]. But our average age turns out to be lower than that described in the foreign series [3-6]. This age disparity of patients can be explained on the one hand by the fact that the European population is more aging than ours, but also by the precariousness of the preventive measures in our environment making the subjects are exposed at an early age cardiovascular risk factors, 


\begin{tabular}{|c|c|c|c|c|c|}
\hline \multicolumn{2}{|c|}{ Parameters } & \multicolumn{2}{|c|}{ Age (years) } & \multirow[t]{2}{*}{$\mathbf{t}$} & \multirow[t]{2}{*}{$p$ value } \\
\hline & & $<65$ & $\geq 65$ & & \\
\hline \multirow[t]{2}{*}{$\%$ ARA } & Before & $60 \pm 17$ & $32 \pm 15$ & 4.150 & 0.001 \\
\hline & After & $74 \pm 15$ & $42 \pm 13$ & 5.45 & 0.001 \\
\hline \multirow[t]{2}{*}{ \% Fugl Meyer } & Before & $59 \pm 18$ & $31 \pm 14$ & 4.012 & 0.042 \\
\hline & After & $72 \pm 15$ & $49 \pm 12$ & 4.021 & 0.006 \\
\hline
\end{tabular}

Data are shown mean \pm Standard deviation. ARA $=$ Action Research Arm

including stroke.

The majority of these patients had ischemic stroke (70\%), and the left hemi-body was most interested in paralysis or paresis $(60 \%)$. Most of them were beyond one year of their illness $(53.3 \%$ of cases between 6 and 11 months of illness, and $46.7 \%$ at least 12 months).

In relation to the level of motor, functional and autonomy evolution of these patients before the program, it appears that it was practically average, ie an overall average score of ARA (motor level of the upper limb) to $51 \%$ and a motor level at the Fugl meyer scale overall at 50\%. This level of motor and average autonomy found in these patients at the beginning of the program can be explained because they were already at least 6 months of their stroke, considered as phase of maintenance in community [7], which is not possible only when the range score is normally $\geq 60 / 100$ [8]. In addition, Fugl Meyer's hand motility was the most disturbed (at 6/14), with a pinch score at the lower ARA (ie 3/18) than the others under scales. This tendency can be justified first of all by the fact of the important representation of the hand at the level of the brain (homunculus of penfil), and by its motricity which is more fine and discriminative than the other parts of the body.

By analyzing the impact of stress-induced therapy on the various motor, functional and autonomy parameters selected, we recorded a very significant difference in their overall mean values. Including an ARA score of $51 \pm 21 \%$ at baseline and $64 \pm 20 \%$ at the end of treatment, with a $p=0.001$; on the other hand, the analysis of the subscores did not show any significant difference in pinching (initially $3 / 18$ for $4 / 18$ at the end) and overall movements (5/9 initially for $6 / 9$ at the end), with a $p>0.05$. The difference in mean values at the Fugl Meyer scale was also very significant, both at overall scores and under-scores ( $p$ $<0.05)$. Our results corroborate with those of Bofosa et al. [5] who compared the level of motor development among patients undergoing induced stress therapy (IDC) found a very significant improvement $(p=0.001)$ for the group of patients undergoing TCI at the end of the program.

The good motor evolution observed after induced stress has been demonstrated in the randomized Excite study by Wolf et al. [9], published in 2006, justified by its intensive character, it significantly improves the quality and speed of movement in the patients who practice it.

Moreover, it is currently reported that rehabilitation is giving more and more place to assets; Daviet [10] synthesized the main studies validating the principles of motor learning insisting on active patient participation, the need for repeated gestures, in an intense and task-oriented way. This trend is very much in TCI, and plays a key role in brain plasticity.

As for the comparison of the mean values of the overall ARA and Fugl Meyer scores made according to the duration of the disease, we found no significant difference between patients who were less than 12 months old and those who more or less 12 months ( $p$ $>0.05)$. This comparison also showed no significant difference between men and women $(p>0.05)$.

The same observation was made in the series of Tshianga [11], where the difference was not significant between men and women for both motor skills score $(p=0.89)$ and autonomy score $(p=0.86)$. This trend has been reported in almost all literature and reviews [12-17] that sex does not appear to have an influence on functional outcome.

On the other hand, we found a very significant difference between the mean values of the overall 
scores of the motor and independence scales between elderly patients (over 65) and younger patients (under 65) $(p<0.05)$.

Tshianga $[11,15]$ in his series also found a very significant influence of age on the level of gross motor skills $(p=0.001)$ and autonomy $(p=0.002)$, ie better for patients under 65 than those over 65 . However, there is controversy in the literature about the impact of age on functional becoming. Feigenson et al. [18], in a prospective study of 248 patients, does not retain age as a predictor of fate. Granger et al. [19] reported that old age significantly reduces the level of final functional independence. These disparities may be related to sample size, past lifestyle and other related factors, as some authors have reported that although recent work finds a relationship between age and functional becoming, it is note that the weight of age in functional becoming is less than that of other predictors $[18,19]$.

\section{Limitations}

This study is limited to the use of a small sample of a metropolitan city of the Democratic Republic of Congo and in the absence of control or comparative group, which will probably reduce the possibility of generalization of the results. Therefore, a future study of a more representative sample of hemiplegic patients and adding the control or comparative groupis needed to potentially increase the generalizability in the country.

\section{CONCLUSION}

This study shows that induced stress therapy has positive effects in motor and functional recovery of the upper hemiplegic limb. Sex and duration of illness were not positively influenced. On the other hand, the influence of age has been found. These results concern only the cases included in the study.

\section{Conflict of interest}

The authors disclosed no conflict of interest during the preparation or publication of this manuscript.

\section{Financing}

The authors disclosed that they did not receive any grant during conduction or writing of this study.

\section{REFERENCES}

1. Bossa D. Guide pratique en cas d'hémiplégie, vignot édition, Paris, 1999: p. 255.

2. Person M. La rééducation de la préhension après un accident vasculaire cérébral: l'apport des nouvelles techniques. Kinesither Scient 2009;505:32-9. [Article in French]

3. Picard Y. Evaluation clinique de la motricité d'une personne adulte atteinte d'hémiplégie. Motricité cérébrale 2003;24:81-107. 4. Blanchard M. Vade-mecum de médecine pratique, 8ème édition, Masson et Cie, Paris, 2002: p. 277.

5. Bofosa T, Kam E, Njimbu F, Mpefi P, Kayembe T, Miagindula $\mathrm{B}$, Impact of a program of induced stress therapy on the motor and functional recovery of the upper limb of hemiplegic patients in Kinshasa, Democratic Republic of Congo. J Surg Med 2018;2:339-43.

6. Kam E, Bofosa T, Lempira F, Malemba A, Nkongo H, Nkiama $\mathrm{C}$, et al. Impact of lack of rehabilitation follow-up care on the functional level and autonomy of vascular hemiplegic patients at Kinshasa University clinics on homecoming. Med Sci Discovery 2018;5:274-78.

7. Recommandations de bonne pratique Accident vasculaire cérébral: Prise en charge précoce (alerte, phase pré hospitalière, phase hospitalière initiale, indications de la thrombolyse) HAS 2009.

8. Fery-Lemonniere E. Prévention et prise en charge des accidents vasculaires cérébraux en France, Rapport présentés au Ministère de la Santé et des Sports, ISRN SAN-DHOS/RE-092-FR, Juin 2009.

9. Wolf SL, Winstein CJ, Miller JP, Taub E, Uswatte G, Morris $\mathrm{D}$, et al. Effect of constraint-induced movement therapy on upper extremity function 3 to 9 months after stroke. The EXCITE randomized clinical trial. JAMA 2006,296:2095-104.

10. Daviet JC. Facteurs prédictifs du devenir vital et fonctionnel d'une cohorte d'hémiplégiques vasculaires. Conséquences sur les modalités de prise en charge, Thèse, Faculté de Médecine, Université Limoges; 2004.

11. Tshianga H. Trajectoires de services de réadaptation postAVC Un continuum centré sur la personne, Rapport du Comité d'experts sur l'offre de services de réadaptation post-AVC Présidé par Carol L. Richards, O.C., Québec 2013.

12. Langhorne P, Coupar F, Pollock A. Motor recovery after stroke: a systematic review. Lancet Neurol 2009;8:741-54.

13. Carlsson CM, Stein JH. Cardiovascular diseases and the aging woman: overcoming barriers to lifestyle changes. Curr Womens Health Rep 2002;2:366-72.

14. Robinson RG. Poststroke depression: prevalence, diagnosis, treatment, and disease progression. Biol Psychiatry 2003;54:37687.

15. Tshianga $H$. Impact des troubles cognitifs sur la récupération fonctionnelle et l'autonomie des patients en post AVC, Mémoire, Faculté de Médecine, Université de Kinshasa, Juin 2018.

16. Petit H. [What is the impact of initial prognosis factors on the efficacy and indications of rehabilitation following stroke?] Ann Readapt Med Phys 1997;40:113-20. [Article in French] 17. Meijer R, Ihnenfeldt DS, Van Limbeek J, Vermeulen M, Haan 
RJ. Prognostic factors for ambulation and activities of daily living in the subacute phase after stroke. A systematic review of the literature. Clin Rehabil 2003;17:119-29.

18. Feigenson JS, McCarthy ML, Greenberg SD, Feigenson WD. Factors influencing outcome and length of stay in a stroke rehabilitation unit. Part 2. Comparison of 318 screened and 248 unscreened patients. Stroke 1977; 8:651-62.

19. Granger CV, Hamilton BB, Fiedler RC. Discharge outcome after stroke rehabilitation. Stroke 1992;23:978-82. 